\title{
THERMODYNAMIC STUDY OF THE RETENTION OF AROMATIC HYDROCARBONS ON PHENYLSILICAGEL BASED STATIONARY PHASE UNDER REVERSED-PHASE LIQUID CHROMATOGRAPHIC MECHANISM
}

\author{
Andreia-Cristina SOARE, ${ }^{\mathrm{a}}$ Viorica MELTZER, ${ }^{\mathrm{b}}$ Mihaela CHEREGI ${ }^{\mathrm{a}}$ and Victor DAVID ${ }^{\mathrm{a},{ }^{*}}$ \\ ${ }^{\text {a }}$ University of Bucharest, Faculty of Chemistry, Department of Analytical Chemistry, \\ Sos. Panduri, no. 90, 050663, Bucharest, Roumania \\ ${ }^{\mathrm{b}}$ University of Bucharest, Faculty of Chemistry, Department of Physical Chemistry, \\ Bd. Regina Elisabeta 4-12, Bucharest, 030018, Bucharest, Roumania
}

The retention behavior of some aromatic hydrocarbons on phenylsilicagel stationary phase was studied for the temperature interval between $20^{\circ} \mathrm{C}$ and $50^{\circ} \mathrm{C}$. The van't Hoff plots were studied for some mobile phase compositions, using acetonitrile or methanol as organic additive. The variation of the standard enthalpy was calculated from the slope of these linear plots and its dependence on the mobile phase composition was rather different for the two organic modifiers. The variation of the standard enthalpy was very small for the four aromatic hydrocarbons in case of using acetonitrile (from -11.07 $\mathrm{kJ} / \mathrm{mol}$ for benzene to $11.49 \mathrm{~kJ} / \mathrm{mol}$ for propylbenzene; mobile phase composition being 45/55, v/v, acetonitrile/water), while for methanol used as organic modifier the variation of standard enthalpy changed significantly from benzene to propylbenzene (-10.92 $\mathrm{kJ} / \mathrm{mol}$ for benzene to $-18.58 \mathrm{~kJ} / \mathrm{mol}$ for propylbenzene; mobile phase composition - 45/55, v/v, methanol/water). The variations of the standard entropy and Gibbs free energy change for the hydrocarbons were estimated considering a phase ratio of 0.25 for the column used.

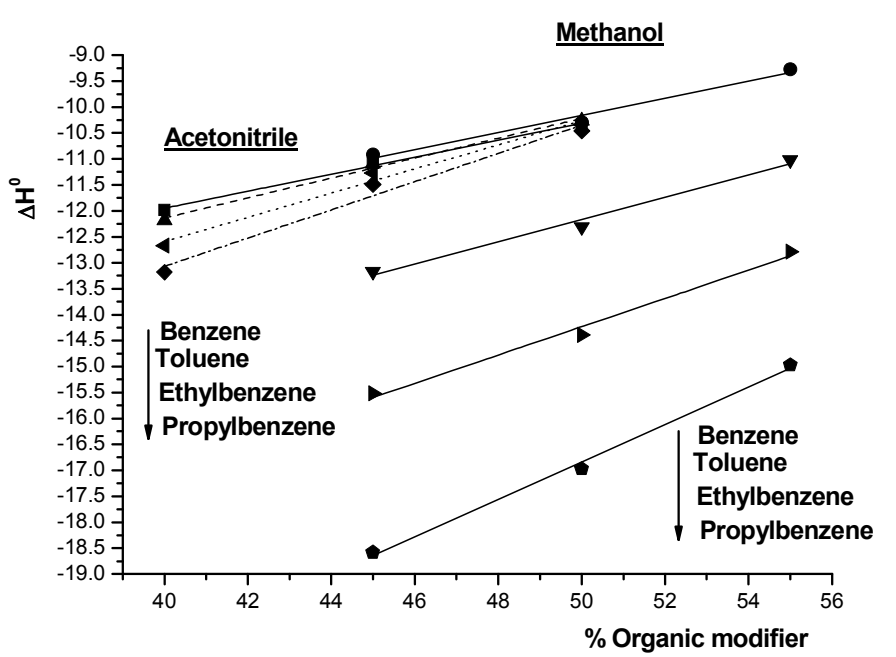

\section{INTRODUCTION}

Temperature is a main parameter in reversedphase liquid chromatography (RP-LC) influencing the retention and peak performances of the investigated compounds. ${ }^{1-3}$ The retention of studied analytes is basically described by the linear dependence between the natural logarithm of the retention factor $k$ and the inverse value of the absolute column temperature $(1 / \mathrm{T})$, known as the van't Hoff rule: ${ }^{4}$

$$
\ln \mathrm{k}=-\frac{\Delta \mathrm{H}^{0}}{\mathrm{R} \cdot \mathrm{T}}+\frac{\Delta \mathrm{S}^{0}}{\mathrm{R}}+\ln \Phi
$$

In eq. $1, \Delta H^{0}$ and $\Delta S^{0}$ are representing the variations of the standard enthalpy, and the standard entropy, respectively, for the transfer of the analyte from the mobile phase to the stationary

\footnotetext{
* Corresponding author: victor.david@chimie.unibuc.ro
} 
phase, $\Phi$ represents the phase ratio of the used chromatographic column (i.e. the ratio between the volume of stationary phase and the volume of mobile phase) ${ }^{5}$ and $R$ is the universal gas constant $\left(8.314 \mathrm{~J} \mathrm{~K}^{-1} \mathrm{~mol}^{-1}\right)$. According to the van't Hoff rule, the dependence between $\ln k$ and $1 / \mathrm{T}$ should be linear, unless some other equilibria interfere with the retention process and deviate this dependence from the linearity. ${ }^{6-9}$ This was applied for a large number of organic compounds and under various elution conditions, by using the common RP-LC stationary phases (C8 or C18).

Unlike RP-LC based on octyl or octadecylsilicagel when the interaction between analyte and stationary phase is dominated by the van der Waals forces, in case of RP-LC based on phenylsilicagel stationary phase this interaction becomes a combination of van der Waals with $\pi-\pi$ forces. ${ }^{10}$ The last type can be suppressed by the presence of acetonitrile in mobile phase, which interacts also with stationary phase. ${ }^{11}$ This effect can have significant influence on the selectivity of the chromatographic separations obtained on phenylsilicagel stationary phase compared to the standard octyl or octadecilsilicagel, typically used in reversed-phase mechanism. ${ }^{12,13}$ From this point of view significant differences are assumed to be observed in the influence of temperature on the retention of aromatic compounds by using mobile phases containing methanol versus acetonitrile in their composition. It is the aim of this study to investigate the influence of column temperature on the retention of some aromatic hydrocarbons, and to compare the thermodynamic parameters of the partition of these compounds between mobile phase containing these organic modifiers and phenylsilicagel stationary phase.

\section{EXPERIMENTAL}

This study was carried out with an Agilent 1100 Series liquid chromatograph (Agilent Technologies) having the following configuration: degasser (G1379A), binary pump (G1312A), auto sampler (G1313A), column thermostat (G1316A), and diode array detector (G1315A). Chromatographic data were acquired by means of Agilent Chemstation software rev. B.01.03. A Zorbax Eclipse XDB-Phenyl (length: $150 \mathrm{~mm}$; inner diameter: $4.6 \mathrm{~mm}$; particle diameter: $5 \mu \mathrm{m}$; carbon load: $7.2 \%$; surface area: $180 \mathrm{~m}^{2} / \mathrm{g}$; pore size: $80 \AA$ ) was used in this study.

All solvents were HPLC (gradient) grade. Acetonitrile and methanol were purchased from Sigma-Aldrich (Germany). Water (resistivity minimum $18.2 \mathrm{M} \Omega$ and TOC maximum 30 $\mathrm{ppb)}$ was produced within the laboratory with a TKA Lab HP 6UV/UF instrument.
Mobile phase composition was based on acetonitrile, or methanol, and water, in the proportion $(\mathrm{v} / \mathrm{v})$ indicated in the next section. Standard solutions containing $125 \mu \mathrm{g} / \mathrm{mL}$ of each hydrocarbon, in methanol, were injected with a volume of 1 $\mu \mathrm{L}$. The column temperature was set up to $20^{\circ} \mathrm{C}, 25^{\circ} \mathrm{C}, 30^{\circ} \mathrm{C}$, $35^{\circ} \mathrm{C}, 40^{\circ} \mathrm{C}, 45^{\circ} \mathrm{C}$ and $50^{\circ} \mathrm{C}$. UV detection was done at 254 $\mathrm{nm}$.

The value of retention factor $k$ was calculated for each studied aromatic hydrocarbon with the formula $k=\left(\mathrm{t}_{\mathrm{r}}-\mathrm{t}_{0}\right) / \mathrm{t}_{0}$, where the $t_{r}$ represents the retention time (in minutes) for the hydrocarbon. The value of $t_{0}$, representing the dead time of the separation, was measured from the retention time of uracil, under the same chromatographic conditions applied to the studied aromatic hydrocarbons (mobile phase composition and temperature).

\section{RESULTS AND DISCUSSION}

Three compositions of the mobile phase were studied for measuring the retention factor of the four aromatic hydrocarbons (benzene, toluene, ethylbenzene and propylbenzene): 40,45 and 50\% acetonitrile and 45, 50 and 55\% methanol. The retention time ( $t_{r}$, in $\left.\min \right)$ of the studied hydrocarbons was measured for each set-up mobile phase composition and all column temperatures indicated in Experimental section. An example of their separation at the used column temperatures and a specified mobile phase composition is shown in Fig. 1. Each chromatographic peak was characterized by high symmetry $(>0.9)$, and high values of the chromatographic resolution between each consecutive pair of hydrocarbons.

The van't Hoff plots for each mobile phase composition (an example of such dependence is depicted in Fig. 2 for a given mobile phase composition) were obtained and described by the empirical equation:

$$
\ln k=a+b \cdot \frac{1}{T}
$$

The values of slope $b$ and intercept $a$, as well as the determination coefficient $r^{2}$, obtained from the linear regression applied to the dependences between experimental values of $\ln k$ and $1 / T$ are given in Table 1. All plots are characterized by acceptable determination coefficients $\left(\mathrm{r}^{2}>0.9900\right)$. The values of the slope and the intercepts can then be used in calculating some thermodynamic parameters of the chromatographic process. Thus, the slope $b$ can be used for calculating the variation of the standard enthalpy $\Delta H^{0}$, associated to the transfer of the studied hydrocarbon from mobile phase to the stationary phase: $\Delta H^{0}=-b \cdot R$. 


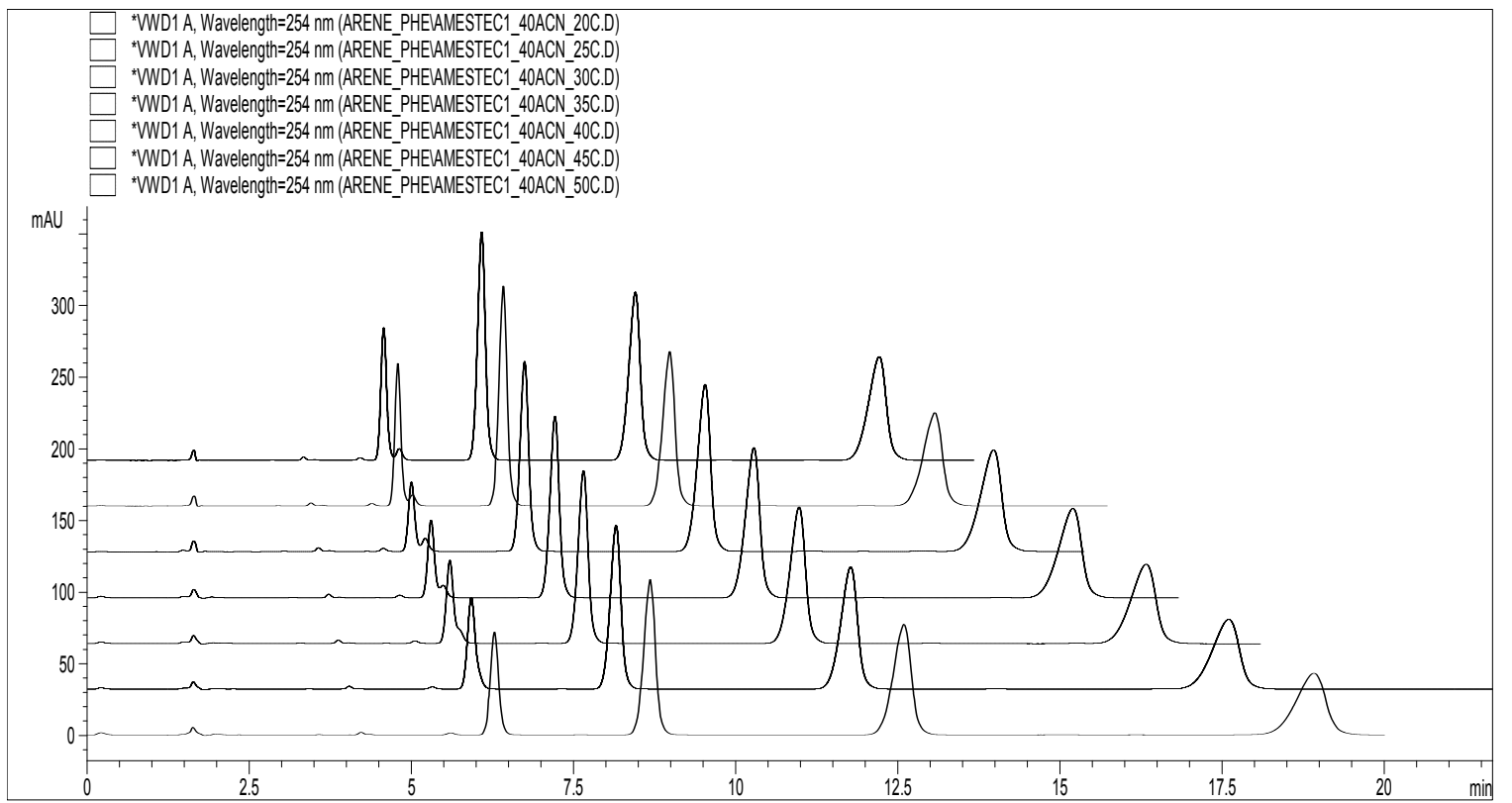

Fig. 1 - Overlaid chromatograms of the separation of benzene, toluene, ethylbenzene and propylbenzene (in this elution order) at set-up column temperatures and a mobile phase with composition: $40 \%$ acetonitrile and $60 \%$ water (v/v).

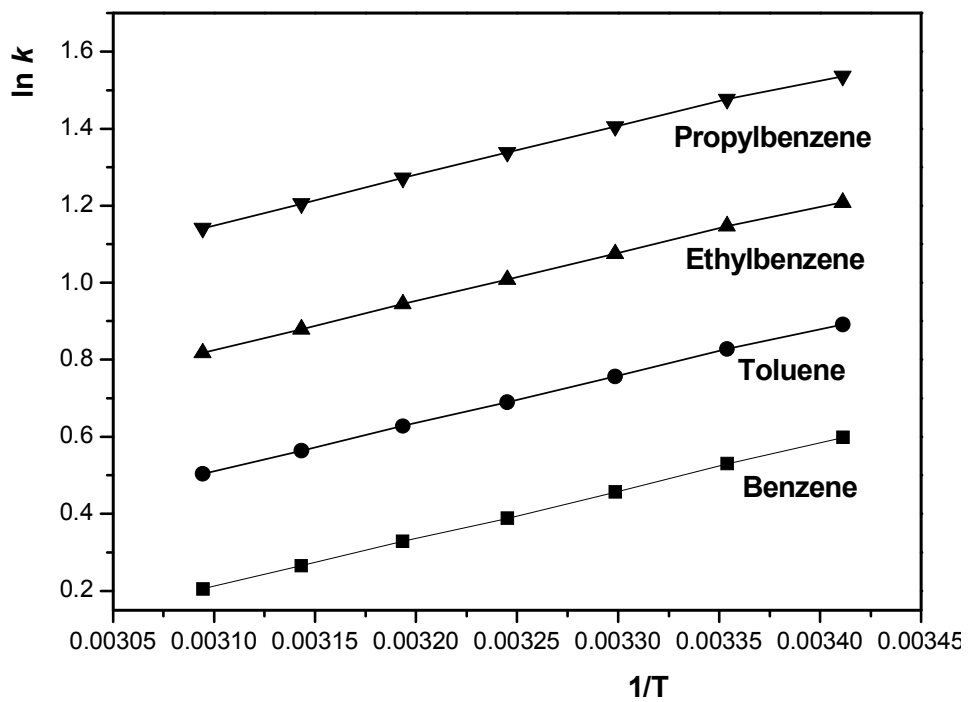

Fig. 2 - Dependence of the experimental values of $k$ on $1 / \mathrm{T}$

for the studied aromatic hydrocarbons for mobile phase $50 \% \mathrm{ACN}$ and $50 \%$ water.

\section{Table 1}

Regression parameters calculated for the linear dependences for the four studied hydrocarbons, on different mobile phases

\begin{tabular}{c|c|c|c|c|c}
\hline Mobile phase & $\begin{array}{c}\text { Linear } \\
\text { regression } \\
\text { parameters }\end{array}$ & Benzene & Toluene & Ethylbenzene & Propylbenzene \\
\hline $40 \%$ ACN & $\mathrm{a}$ & -3.715 & -3.394 & -3.161 & -2.916 \\
$60 \%$ water & $\mathrm{b}$ & 1440.46 & 1465.21 & 1524.47 & 1585.06 \\
& $\mathrm{r}^{2}$ & 0.9995 & 0.9996 & 0.9994 & 0.9992 \\
\hline $45 \%$ ACN & $\mathrm{a}$ & -3.639 & -3.301 & -3.006 & -2.712 \\
$55 \%$ water & $\mathrm{b}$ & 1331.83 & 1333.72 & 1355.67 & 1382.03 \\
& $\mathrm{r}^{2}$ & 0.9997 & 0.9997 & 0.9995 & 0.9991 \\
\hline $50 \%$ ACN & $\mathrm{a}$ & -3.644 & -3.315 & -3.028 & -2.748 \\
$50 \%$ water & $\mathrm{b}$ & 1243.62 & 1234.27 & 1243.74 & 1258.29 \\
& $\mathrm{r}^{2}$ & 0.9997 & 0.9997 & 0.9993 & 0.9987
\end{tabular}


Table 1 (continued)

\begin{tabular}{c|c|c|c|c|c}
\hline \multirow{2}{*}{$45 \% \mathrm{MeOH}$} & $\mathrm{a}$ & -3.448 & -3.692 & -3.972 & -4.460 \\
$55 \%$ water & $\mathrm{b}$ & 1313.90 & 1584.30 & 1867.23 & 2234.92 \\
& $\mathrm{r}^{2}$ & 0.9978 & 0.9984 & 0.9986 & 0.9988 \\
\hline \multirow{2}{*}{$50 \% \mathrm{MeOH}$} & $\mathrm{a}$ & -3.484 & -3.706 & -3.945 & -4.332 \\
$50 \%$ water & $\mathrm{b}$ & 1237.75 & 1481.01 & 1730.27 & 2041.53 \\
& $\mathrm{r}^{2}$ & 0.9978 & 0.9983 & 0.9985 & 0.9987 \\
\hline \multirow{2}{*}{$55 \% \mathrm{MeOH}$} & $\mathrm{a}$ & -3.392 & -3.564 & -3.752 & -4.059 \\
$45 \%$ water & $\mathrm{b}$ & 1115.57 & 1325.25 & 1538.89 & 1801.02 \\
& $\mathrm{r}^{2}$ & 0.9982 & 0.9984 & 0.9985 & 0.9986 \\
\hline
\end{tabular}

Table 2

The values of standard enthalpy variation $\left(\Delta H^{0}\right)$ of studied hydrocarbons for their transfer from mobile phase to the stationary phase

\begin{tabular}{c|c|c|c|c}
\hline & \multicolumn{4}{|c}{ Standard enthalpy variation $\left(\Delta \mathbf{H}^{\mathbf{0}} \mathbf{\mathbf { k J }} / \mathbf{m o l}\right)$} \\
\hline Mobile phase & Benzene & Toluene & Ethylbenzene & Propylbenzene \\
\hline $\begin{array}{c}40 \% \mathrm{ACN} \\
60 \% \text { water }\end{array}$ & -11.98 & -12.18 & -12.67 & -13.18 \\
\hline $\begin{array}{c}45 \% \mathrm{ACN} \\
55 \% \text { water }\end{array}$ & -11.07 & -11.09 & -11.27 & -11.49 \\
\hline $\begin{array}{c}50 \% \mathrm{ACN} \\
50 \% \text { water }\end{array}$ & -10.34 & -10.26 & -10.34 & -10.46 \\
\hline $\begin{array}{c}45 \% \mathrm{MeOH} \\
55 \% \mathrm{water}\end{array}$ & -10.92 & -13.17 & -15.52 & -18.58 \\
\hline $\begin{array}{c}50 \% \mathrm{MeOH} \\
50 \% \mathrm{water}\end{array}$ & -10.29 & -12.31 & -14.39 & -16.97 \\
\hline $\begin{array}{c}55 \% \mathrm{MeOH} \\
45 \% \mathrm{water}\end{array}$ & -9.27 & -11.02 & -12.79 & -14.97 \\
\hline
\end{tabular}

The values of the slope for the four studied hydrocarbons and six mobile phase compositions were thus used in calculating the standard enthalpy variation $\left(\Delta H^{0}\right)$ for the transfer of solute from mobile phase to the stationary phase, whose values are given in Table 2. For a better observation of their trends, as the dependence of $\Delta H^{0}(\mathrm{~kJ} / \mathrm{mol})$ on the mobile phase composition, a graphical representation is depicted in Fig. 3.

The value of the standard enthalpy variation increases with the increase of the hydrophobic character of the aromatic hydrocarbon, which influences the interaction of aromatic hydrocarbon with the phenylsilicagel stationary phase. Thus, the highest values for $\Delta H^{0}$ were obtained for propylbenzene, for all six mobile phase compositions. The experimental values of $\Delta H^{0}$ from this study are in good accordance with theoretical values calculated for the stacking interactions between two aromatic rings. ${ }^{14}$

The main observation from Fig. 3 is the small differences of $\Delta H^{0}$ for the four studied aromatic hydrocarbons in case of using acetonitrile as organic modifier in mobile phase composition. In this case, small differences can also be noticed for $H^{0}$ for the three mobile phase composition, compared to methanol used as organic modifier.
This influence of acetonitrile on the values of $H^{0}$ can be assigned to its suppression effect of the $\pi-\pi$ interactions between aromatic hydrocarbons and phenyl rings attached to the silicagel surface. Methanol and water can only be involved in weak H-bonds with aromatic structures, ${ }^{15}$ and they can not suppress the van de Waals forces between solute and stationary phase.

The calculation of the variation of the standard entropy corresponding to the analyte transfer from mobile phase to the stationary phase is more difficult, due to the term in eq. 1 containing the phase ratio:

$$
\Delta \mathrm{S}^{0}=\mathrm{R}(\mathrm{a}-\ln \Phi)
$$

Some approximations can be however made to calculate $\Delta S^{0}$ from the van't Hoff plots. A first assumption is that the variation of $\Phi$ with temperature is small within the temperature interval used in this study. A fair approximation ${ }^{\text {16- }}$ 18 of the phase ratio value could be considered within the interval $0.20-0.25$. These extreme values can be used $\Delta S^{0}$ with the eq. 3 . Thus, for the highest value of $\Phi$, i.e. 0.25 , the values of the standard entropy variation $\left(\Delta S^{0}\right)$ are given in Table 3. 


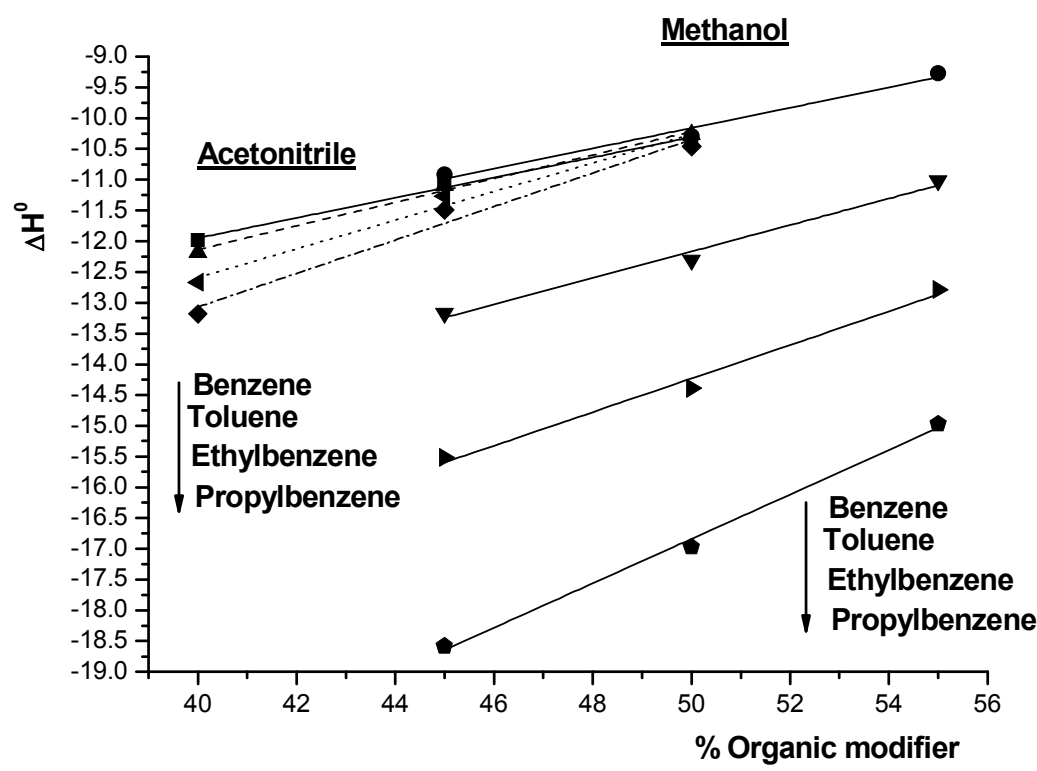

Fig. 3 - Dependence of the standard enthalpy variation $\left(\Delta H^{0}\right)$ of the transfer of aromatic hydrocarbon from mobile to the stationary phase with the content of mobile phase in organic modifier (acetonitrile versus methanol).

Table 3

The values of the standard entropy variation $\left(\Delta S^{0}\right)$ of studied hydrocarbons for their transfer from mobile phase to the stationary phase $\left[\Phi=0.25 ; \Delta S^{0}=8.314(a+1.386)\right]$

\begin{tabular}{c|c|c|c|c}
\hline & \multicolumn{4}{|c}{ Standard enthalpy variation $\left(\Delta \mathbf{S}^{\mathbf{0}}, \mathbf{J} / \mathbf{m o l} \cdot \mathbf{K}\right)$} \\
\hline Mobile phase & Benzene & Toluene & Ethylbenzene & Propylbenzene \\
\hline $\begin{array}{c}40 \% \mathrm{ACN} \\
60 \% \text { water }\end{array}$ & -19.26 & -16.69 & -14.75 & -12.72 \\
\hline $\begin{array}{c}45 \% \mathrm{ACN} \\
55 \% \text { water }\end{array}$ & -18.73 & -15.92 & -13.47 & -11.02 \\
\hline $\begin{array}{c}50 \% \mathrm{ACN} \\
50 \% \text { water }\end{array}$ & -18.77 & -16.04 & -13.65 & -11.32 \\
\hline $\begin{array}{c}45 \% \mathrm{MeOH} \\
55 \% \text { water }\end{array}$ & -17.14 & -19.17 & -21.50 & -25.55 \\
\hline $\begin{array}{c}50 \% \mathrm{MeOH} \\
50 \% \mathrm{water}\end{array}$ & -17.44 & -19.29 & -21.27 & -24.49 \\
\hline $\begin{array}{c}55 \% \mathrm{MeOH} \\
45 \% \mathrm{water}\end{array}$ & -16.68 & -18.11 & -19.67 & -22.22 \\
\hline
\end{tabular}

Table 4

The values of Gibbs free energy change $\left(\Delta G^{0}\right)$ of studied hydrocarbons for their transfer from mobile phase to the stationary phase $\left[\mathrm{T}=298.15 \mathrm{~K} ; \Phi=0.25 ; \Delta S^{0}=8.314(a+1.386)\right]$

\begin{tabular}{c|c|c|c|c}
\hline & \multicolumn{4}{|c}{ Standard free enthalpy variation $\left(\Delta \boldsymbol{G}^{\mathbf{0}} \mathbf{k J} / \mathbf{m o l}\right)$} \\
\hline Mobile phase & Benzene & Toluene & Ethylbenzene & Propylbenzene \\
\hline $\begin{array}{c}40 \% \mathrm{ACN} \\
60 \% \text { water }\end{array}$ & -6.20 & -7.21 & -8.28 & -9.38 \\
\hline $\begin{array}{c}45 \% \mathrm{ACN} \\
55 \% \text { water }\end{array}$ & -5.49 & -6.34 & -7.26 & -8.20 \\
\hline $\begin{array}{c}50 \% \mathrm{ACN} \\
50 \% \text { water }\end{array}$ & -4.74 & -5.48 & -6.27 & -7.09 \\
\hline $\begin{array}{c}45 \% \mathrm{MeOH} \\
55 \% \text { water }\end{array}$ & -5.81 & -7.46 & -9.11 & -10.96 \\
\hline $\begin{array}{c}50 \% \mathrm{MeOH} \\
50 \% \text { water }\end{array}$ & -5.09 & -6.56 & -8.04 & -9.67 \\
\hline $\begin{array}{c}55 \% \mathrm{MeOH} \\
45 \% \mathrm{water}\end{array}$ & -4.30 & -5.62 & -6.93 & -8.35 \\
\hline
\end{tabular}


The Gibbs free energy change for the analyte $i$ $\left(\Delta G_{i}\right)$ at various column temperatures $(\mathrm{T})$ is related to the enthalpy variation $\left(\Delta H_{i}\right)$ and the entropy variation $\left(\Delta S_{i}\right)$ by the Gibbs-Helmholtz equation:

$$
\Delta \mathrm{G}_{\mathrm{i}}=\Delta \mathrm{H}_{\mathrm{i}}-\mathrm{T} \Delta \mathrm{S}_{\mathrm{i}}
$$

The values of $\Delta G_{i}$ at $25^{\circ} \mathrm{C}$ are given in Table 4 , considering the phase ratio parameter used for estimating the entropic contribution to the partition process given in Table 3. As can be observed $\Delta G$ increases from benzene to propylbenzene for each mobile phase composition. On the other hand, the value of $\Delta G$ is influenced by the mobile phase composition, and the $\Delta G$ decreases with the increase of content of the organic modifier in the mobile phase composition. This is in accordance with other

previous thermodynamic studies of the retention process in RP-LC, under similar elution conditions. ${ }^{3,19-22}$

An important chromatographic parameter that can be estimated from the thermodynamic model applied to the LC partition process is the separation selectivity. ${ }^{23}$ The separation selectivity between two analytes, $i$ and $j$, denoted by $\alpha_{i j}$, with the elution order $k_{j}>k_{i}$, is defined by the ratio $k_{j} / k_{i}$, and by using the previous relationships, this becomes:

$$
\begin{aligned}
& \ln k_{i}=-\frac{\Delta G_{i}}{R T} \\
& \ln k_{j}=-\frac{\Delta G_{j}}{R T}
\end{aligned}
$$

Table 5

The calculated and experimental values for separation selectivity $\left(\alpha_{i j}\right)$ between consecutive aromatic hydrocarbons at different column temperature for a mobile phase containing $40 \%$ acetonitrile and $60 \%$ water $(\mathrm{v} / \mathrm{v})$

\begin{tabular}{c|c|c|c|c|c|c}
\hline \multirow{2}{*}{ Temperature (K) } & \multicolumn{2}{|c|}{$\alpha_{\text {benzene/toluene }}$} & \multicolumn{2}{c|}{$\alpha_{\text {toluenelethylbenzene }}$} & \multicolumn{2}{c}{$\alpha_{\text {ethylbenzene/propylbenzene }}$} \\
\cline { 2 - 6 } & calculated & measured & calculated & measured & calculated & measured \\
\hline 293.15 & 1.508 & 1.497 & 1.551 & 1.540 & 1.577 & 1.567 \\
298.15 & 1.497 & 1.499 & 1.539 & 1.540 & 1.565 & 1.565 \\
303.15 & 1.487 & 1.499 & 1.529 & 1.537 & 1.553 & 1.562 \\
308.15 & 1.478 & 1.497 & 1.518 & 1.533 & 1.542 & 1.557 \\
313.15 & 1.469 & 1.493 & 1.508 & 1.525 & 1.532 & 1.551 \\
318.15 & 1.460 & 1.490 & 1.498 & 1.518 & 1.522 & 1.544 \\
323.15 & 1.451 & 1.487 & 1.489 & 1.513 & 1.512 & 1.538 \\
\hline
\end{tabular}

A comparison of the calculated values of $\alpha_{i j}$ at various set-up column temperatures by means of eq. 7 with the experimental values measured from the recorded chromatograms for a specific mobile phase composition are shown in Table 5. Thus, the agreement between calculated and measured values of separation selectivity is very good. For all set-up temperatures, the separation selectivity decreases with the increase of column temperature, a conclusion that has been emphasized by other previous studies. $^{24-26}$

\section{CONCLUSIONS}

The retention behavior of four aromatic hydrocarbons (benzene to propylbenzene) on phenylsilicagel stationary phase, under reversedphase mechanism, was studied within the temperature interval $\left[20 ; 50^{\circ} \mathrm{C}\right]$. The variation of the standard enthalpy was calculated from the slope of the van't Hoff plots for each hydrocarbon and it was shown that this depends on the mobile phase composition for the two organic modifiers. The variation of the standard enthalpy was very small between the four aromatic hydrocarbons in case of using acetonitrile (from $-11.07 \mathrm{~kJ} / \mathrm{mol}$ for benzene to $11.49 \mathrm{~kJ} / \mathrm{mol}$ for propylbenzene and a mobile phase composition of $45 / 55, \quad \mathrm{v} / \mathrm{v}$, acetonitrile/water). For methanol used as organic modifier the variation of standard enthalpy changed significantly from benzene to propylbenzene $(-10.92 \mathrm{~kJ} / \mathrm{mol}$ for benzene to $-18.58 \mathrm{~kJ} / \mathrm{mol}$ for propylbenzene; mobile phase composition $-45 / 55, \mathrm{v} / \mathrm{v}$, methanol/water). The other thermodynamic parameters of the partition process, namely the variations of the standard entropy and Gibbs free energy change for the hydrocarbons, were estimated considering an approximate value of the phase ratio for the column used. 


\section{REFERENCES}

1. Gy. Vigh and Z. Varga-Puchony, J. Chromatogr. A, 1980, 196, 1-9.

2. C. Waterlot and A. Goulas, J. Chem., 2016, article ID 7294105.

3. D. Guillarme, S. Heinisch and J. L. Rocca, J. Chromatogr. A, 2004, 1052, 39-51.

4. A. Vailaya, J. Liq. Chromatogr. Rel. Technol., 2005, 28, 965-1054.

5. S. C. Moldoveanu, E. Caiali and V. David, Chromatographia, 2017, 80, 1491-1500.

6. C. Horvath and W. Melander, "Reversed-phase chromatography", in C. Horvath (Ed.), "High Performance Liquid Chromatography Advances and Perspectives", vol. 2, Academic Press, New York, 1980, p. 199-201.

7. S. Heinisch, G. Puy, M. P. Barrioulet and J. L. Rocca, J. Chromatogr. A, 2006, 1118, 234-243.

8. T. Galaon and V. David, J. Sep. Sci., 2011, 34, 1423-1428.

9. T. Galaon, D. F. Anghel, V. David and H. Y. Aboul-Enein, Chromatographia, 2013, 76, 1623-1630.

10. E. Caiali and V. David, Rev. Roum. Chim., 2019, 64, 367372.

11. M. Yang, S. Fazio, D. Munch and P. Drumm, J. Chromatogr. A, 2005, 1097, 124-129.

12. W. R. Melander, J.-X. Huang, Cs. Horváth, R. W. Stout and J. J. DeStefano, Chromatographia, 1985, 20, 641-651.
13. U. D. Neue, J. E. O'Gara and A. Méndez, J. Chromatogr. A, 2006, 1127, 161-174.

14. W. G. Benjamin, X. Xiaowen and Z. Yan, J. Org. Chem., 2007, 72, 2469-2475.

15. P. Schravendijk and N. F. A. van der Vegt, J. Chem. Theory Comput., 2005, 1, 643-652.

16. S. Moldoveanu and V. David, J. Chromatogr. A, 2015, 1381, 194-201.

17. E. Caiali, V. David, H. Y. Aboul-Enein and S. C. Moldoveanu, J. Chromatogr. A, 2016, 1435, 85-91.

18. J. Rybka, A. Holtzel, A. Steihoff and U. Tallarek, J. Phys. Chem. C, 2019, 123, 3672-3681.

19. S. Bocian, J. Soukup, P. Jandera and B. Buszewski, Chromatographia, 2015, 78, 21-30.

20. M. Kaczmarek, A. Buciński, M. P. Marszall, A. Badura and R. Kaliszan, J. Liq. Chromatogr. Rel. Technol., 2015, 38, 62-67.

21. E. Lundanes and T. Greibrokk, Adv. Chromatogr., 2006, 44, 45-77.

22. S. Heinisch and J.-L. Rocca, J. Chromatogr. A, 2009, 1216, 642-658.

23. S. C. Moldoveanu, E. Caiali and V. David, J. Liq. Chromatogr. Rel. Technol., 2018, 41, 24-32.

24. J. W. Dolan, J. Chromatogr. A, 2002, 965, 195-205.

25. L. C. Sander and S. A. Wise, J. Sep. Sci., 2001, 24, 910-920.

26. S.-Y. Han, H.-M. Yu, Y.-Q. Pei and Y.-M. Chi, RSC Advances, 2015, 5, 62686. 
